\title{
Association of maternal chronic disease with risk of congenital heart disease in offspring
}

\author{
Hsin-Hsu Chou MD, Meng-Jiun Chiou MSc, Fu-Wen Liang PhD, Lea-Hua Chen BSc, Tsung-Hsueh Lu MD PhD, \\ Chung-Yi Li PhD
}

Competing interests:

None declared.

This article has been peer reviewed.

Accepted: June 2, 2016

Online: Oct. 11, 2016

Correspondence to: Chung-Yi Li, cyli99@mail. ncku.edu.tw

CMAJ 2016. DOI:10.1503/ cmaj.160061

\begin{abstract}
Background: Information about known risk factors for congenital heart disease is scarce. In this population-based study, we aimed to investigate the relation between maternal chronic disease and congenital heart disease in offspring.
\end{abstract}

Methods: The study cohort consisted of 1387650 live births from 2004 to 2010. We identified chronic disease in mothers and mild and severe forms of congenital heart disease in their offspring from Taiwan's National Health Insurance medical claims. We used multivariable logistic regression analysis to assess the associations of all cases and specific types of congenital heart disease with various maternal chronic diseases.

Results: For mothers with the following chronic diseases, the overall prevalence of congenital heart disease in their children was significantly higher than for mothers without these diseases: diabetes mellitus type 1 (adjusted odds ratio [OR] 2.32, 95\% confidence interval $[\mathrm{Cl}]$ 1.66-3.25), diabetes mellitus type 2 (adjusted OR 2.85, 95\% Cl 2.603.12), hypertension (adjusted OR 1.87, 95\% Cl 1.69-2.07), congenital heart defects (adjusted OR 3.05, 95\% Cl 2.45-3.80), anemia (adjusted OR 1.31, 95\% Cl 1.25-1.38), connective tissue disorders (adjusted OR 1.39, 95\% Cl 1.191.62), epilepsy (adjusted OR 1.37, $95 \% \mathrm{Cl} 1.08$ 1.74) and mood disorders (adjusted OR 1.25, 95\% Cl 1.11-1.41). The same pattern held for mild forms of congenital heart disease. A higher prevalence of severe congenital heart disease was seen only among offspring of mothers with congenital heart defects or type 2 diabetes.

Interpretation: The children of women with several kinds of chronic disease appear to be at risk for congenital heart disease. Preconception counselling and optimum treatment of pregnant women with chronic disease would seem prudent.
$\mathrm{C}$ ongenital heart disease is the most common congenital disorder in newborns. Prevalence at birth ranges from 5 to 15 per 1000 live births. ${ }^{1-4}$

Despite advances in pediatric cardiac diagnosis and medical care, congenital heart disease remains the leading cause of perinatal and infant death due to congenital malformations. ${ }^{5,6}$ However, little information is available about the risk factors, especially modifiable environmental and behavioural factors that may have adverse effects on fetal cardiac development; this lack of information represents a great obstacle in the prevention of congenital heart disease. One earlier study suggested that the proportion of cases attributable to these external factors might be as high as $30 \%$ for certain types of congenital heart disease. ${ }^{7}$ Periconceptional intake of multivitamin supplements containing folic acid may reduce the risk in offspring. ${ }^{8,9}$ Maternal lifestyle factors, including cigarette smoking, alcohol consumption and obesity, have also been associated with risk of congenital heart disease. ${ }^{10-12}$ It is also well established that maternal rubella infection during pregnancy can result in offspring with various congenital heart diseases..$^{13}$

Available information about the association of maternal chronic diseases with congenital heart disease is limited. Pregnant women with congenital heart defects are at increased risk of certain congenital heart conditions in their offspring. ${ }^{14}$ Additionally, such diseases in offspring have been associated with maternal pregestational and (less consistently) gestational diabetes. ${ }^{15-17}$ One recent population-based study reported that a number of maternal chronic diseases, including diabetes mellitus, hypertension, connective tissue disorders and congenital heart disease, were associated with an increased risk of congenital heart disease in the offspring. ${ }^{18}$ However, differences 
in incidence and survival among different ethnic groups and geographic areas could be attributable to the variable genetic and environmental backgrounds associated with different locations. ${ }^{19,20}$

We conducted a nationwide populationbased study in Taiwan to further evaluate the potential role of maternal chronic diseases in the risk of congenital heart disease in offspring.

\section{Methods}

\section{Data sources}

We used data from the Taiwan Maternal and Child Health Database, a nationwide populationbased data set established, updated and supervised by the Health and Welfare Data Science Center, Ministry of Health and Welfare, Taiwan. ${ }^{21}$ These data comprise several registration data sets, including Birth Registrations (2004-2011), Birth Notifications (2004-2011), Mortality Registrations (2004-2011) and medical claims of the National Health Insurance program (1998-2011); they cover $99 \%$ of Taiwanese residents and nonTaiwanese individuals permitted to work and study in Taiwan and can be interlinked through encrypted personal identification numbers.

Details of the Taiwan Maternal and Child Health Database have been described elsewhere. ${ }^{22}$ Information from the database has been validated, and a high level of completeness and validity was observed for most of its components. ${ }^{23}$ For the current study, we used all of the component data sets except Mortality Registrations. The Birth Notifications data set provides information on prenatal care and the lifestyle of pregnant women, as well as data on stillbirths and newborn characteristics recorded at birth (e.g., congenital abnormalities and Apgar scores). In Taiwan, it is a legal requirement that all live births and deaths be registered within 10 days. The Birth Registrations data set consists of the sociodemographic characteristics of live births (e.g., infant's sex, birth weight and gestational age; single v. multiple births; and birth order) and of the parents (e.g., age at delivery, education and marital status).

Taiwan's National Health Insurance program was implemented in March 1995, and up to $99 \%$ of the country's 23 million residents receive medical care through this program. More than $96 \%$ of hospitals (including more than 100 regional and tertiary care hospitals) and clinics in Taiwan are contracted to provide health care services that are reimbursed by the National Health Insurance Administration. ${ }^{24}$ For this study, we used both inpatient and outpatient medical claims data from the National Health Insurance program, which provided information on diagnoses and procedures for each clinical visit and admission.

\section{Study design and participants}

Our study was a population-based, nationwide cohort study of live births in Taiwan between 2004 and 2010. For inclusion in the study, gestational age had to be greater than 22 weeks and birth weight had to be at least $500 \mathrm{~g}$, to avoid including live births with an implausible gestational age or birth weight. ${ }^{25}$

\section{Exposure variables}

We identified chronic diseases diagnosed in the mothers before pregnancy from both inpatient and outpatient claims, using codes from the clinical modification of the International Classification of Diseases, 9th Revision (ICD-9-CM; see Table A1 in Appendix 1, available at www.cmaj.ca/lookup/ suppl/doi:10.1503/cmaj.160061/-/DC1). These conditions included pregestational diabetes (both type 1 and type 2), hypertension, congenital heart defects, thyroid disorders, anemia, systemic connective tissue disorders, epilepsy and specific psychologic disorders. We considered these chronic diseases primarily because they were suspected of being associated with congenital heart disease in previous studies. ${ }^{14,16-18}$

\section{Outcome variables}

The outcome variables were any form of congenital heart disease in an infant, as identified by ICD-9-CM codes (see Table A2 in Appendix 1). To avoid including clinically nonsignificant forms or spontaneously resolved defects, we included only those children in whom the lesions were recorded during at least one hospital admission or during more than 3 outpatient clinic visits within 1 year after birth. ${ }^{4,26}$ We defined 2 subgroups according to severity. Tetralogy of Fallot, transposition of the great arteries, double outlet of right ventricle, total anomalous pulmonary venous return, tricuspid atresia, congenital corrected transposition of great arteries, common truncus and common ventricles were classified as severe; all other lesions were classified as mild.

\section{Confounders}

The potential confounders considered in this study were found, in previous studies, to be potentially associated with the risk of congenital heart disease. ${ }^{14,16-18}$ These potential confounders were classified into 3 categories: characteristics of the delivery, sociodemographic and lifestyle characteristics of the mother and characteristics of the infant.

The characteristics of delivery included the type of delivery (single or multiple births) and parity. The maternal sociodemographic and lifestyle characteristics included cigarette smoking and alcohol use, nationality, level of education, age at delivery and father's age at delivery. 
According to information from Taiwan's Ministry of the Interior, Chinese individuals from mainland China accounted for the majority of non-native Taiwanese mothers $(64.6 \%)$, followed by Vietnamese $(21.2 \%)$ and Indonesian $(4.4 \%)$ individuals. $^{27}$ The evaluated characteristics of infants included sex, year of birth and geographic location of the birth site. Adjustments for geographic locations were made to account for possible geographic variations in diagnostic techniques and frequency of screening for congenital heart disease in Taiwan. ${ }^{28}$ These adjustments may help to reduce the effect of urban-rural differences in accessibility to medical health services in Taiwan. ${ }^{29}$ In turn, these adjustments may help to reduce the effect of differences in ascertainment bias by geography.

\section{Statistical analysis}

We calculated the prevalence of all and specific types of congenital heart disease from 2004 to 2010 and used the Poisson regression model to test for trends in the biannual prevalence of these diseases. We assessed the prevalence values for all and specific types of congenital heart disease in association with maternal chronic diseases present before pregnancy, we adjusted for potential confounders using logistic regression models, and we reported the results as adjusted odds ratios (ORs) and 95\% confidence intervals (CIs). Because a mother might have had more than one delivery during the 7-year study period and because there could be geographic clustering of infants' congenital heart diseases, we used a logistic regression model with the generalized estimating equation to account for within-participant correlations of offspring born to the same mothers and offspring residing in the same geographic area to obtain robust standard error estimates. ${ }^{30}$

To assess the potential effect of maternal chronic disease on risk of congenital heart disease in the offspring, we calculated the percent population attributable risk (i.e., the proportion of cases that would have been avoided in the population if the selected maternal chronic disease had been eliminated). ${ }^{31}$ The statistical analysis was performed using SAS software, version 9.3 (SAS Institute), and a 2-tailed $p$ value less than 0.05 was considered statistically significant.

\section{Ethics approval}

This study was approved by the Institutional Review Board of National Cheng Kung University Hospital (B-ER-102-120-t). The privacy of all patients was protected by the encryption of personal identification numbers; therefore, informed consent was not required.

\section{Results}

\section{Risk of congenital heart disease}

After excluding stillbirths and live births with gestational age less than 22 weeks or birth weight less than $500 \mathrm{~g}$, we identified 1387650 live births (delivered by 1059772 mothers) in Taiwan between 2004 and 2010 (Figure 1). For a total of 27240 live births, congenital heart disease was diagnosed during infancy, representing an overall prevalence of 19.63 per 1000 live births. After exclusion of infants with isolated patent ductus arteriosus born before 37 weeks of gestation, the overall prevalence was reduced to 16.92 per 1000 live births (Table 1). The prevalence rate of severe forms was 1.35 per 1000 live births and that of mild forms was 16.57 per 1000 live births (Appendix 2, available at www.cmaj.ca/lookup/suppl/doi:10.1503/ cmaj.160061/-/DC1). Among the severe conditions recorded, tetralogy of Fallot ( 0.58 per 1000 live births), transposition of great arteries ( 0.42 per 1000 live births) and double outlet of the right ventricle ( 0.23 per 1000 live births) were the 3 most numerous. Atrial septal defect (10.29 per 1000 live births), patent ductus arteriosus (5.19 per 1000 live births) and ventricular septal defect (4.92 per 1000 live births) accounted for most of the mild forms of congenital heart disease.

There was no significant secular trend in the overall prevalence of congenital heart disease during the study period (Table 1). However, the prevalence of severe forms showed a significantly declining trend $(p$ for trend $<0.001)$, from 1.52 per 1000 live births in 2004-2005 to 1.11 per 1000 live births in 2010. A significant declining trend was also noted for specific types, including transposition of great arteries, common ventricle, hypoplastic left heart syndrome, common truncus and tricuspid atresia. No significant time trend was observed for the prevalence of mild congenital heart disease, but the prevalence of certain mild forms, including atrial septal defect, patent ductus arteriosus $(\geq 37 \mathrm{wk}$ ) and pulmonary stenosis, showed significant variations over the study period.

\section{Associations between maternal chronic disease and congenital heart disease in offspring}

The prevalence and adjusted ORs for congenital heart disease in relation to parental and infant characteristics are shown in Appendix 1 (see Table A3). Several maternal chronic diseases, specifically type 1 and type 2 diabetes, hypertension, congenital heart defects, anemia, connective tissue disorders, epilepsy and mood disorders, were significantly associated with a 
higher prevalence of any form of congenital heart disease in the offspring (Table 2). The maternal chronic diseases that were significantly associated with mild forms of congenital heart disease in offspring were the same as those significantly associated with all congenital heart diseases (Table 3). However, only maternal congenital heart defects (adjusted OR 6.72, 95\% CI 4.06-11.12) and type 2 diabetes (adjusted OR $2.80,95 \%$ CI 2.04-3.85) were associated with a significantly higher prevalence of severe congenital heart disease in the offspring (Table 3).

\section{Population attributable risk for all congenital heart disease}

The presence of any of the chronic diseases investigated here was associated with a population attributable risk of $5.73 \%$. The highest population attributable risk for a specific chronic disease was noted for anemia $(2.17 \%)$, followed by type 2 diabetes (1.45\%) and hypertension $(0.71 \%)$ (Table 2$)$.

\section{Interpretation}

In this population-based study, we identified a decreasing trend in the prevalence of severe but not mild congenital heart disease from 2004 to 2010 in Taiwan. We also found that several maternal chronic diseases, specifically type 1 and type 2 diabetes, hypertension, congenital heart defects, anemia, connective tissue disorders, epilepsy and mood disorders, were associated with a significantly higher prevalence of overall and mild forms of congenital heart disease in offspring. Only maternal congenital heart defects and type 2 diabetes were significant predictors of severe congenital heart disease in offspring. Although some maternal diseases were associated with congenital heart disease in offspring, caution should be applied in interpreting these associations, because the population attributable risks were very low.

The prevalence of congenital heart disease among Taiwanese infants was relatively higher than the prevalence reported from other countries, which has ranged from 5 to 15 per 1000 live births. ${ }^{1-4}$ Apart from the influence of racial disparities, the increasing utilization of echocardiography in newborns in Taiwan, to facilitate the early diagnosis of mild congenital heart disease, is a possible explanation for this difference, especially in asymptomatic infants., ${ }^{4,32}$

Moreover, the prevalence of congenital heart disease in our study was higher than the prevalence reported in one previous local study, by $\mathrm{Wu}$ and associates, ${ }^{4}$ who used only National Health Insurance claims in their analysis. Med- ical visits by infants under 60 days of age may be reimbursed through National Health Insurance claims under the name of either the father or the mother; however, records for an infant's father and mother cannot be accessed simultaneously. This situation results in incomplete coverage of medical visits by infants with congenital heart disease. ${ }^{33}$ Because such infants (especially those with severe forms) tend to

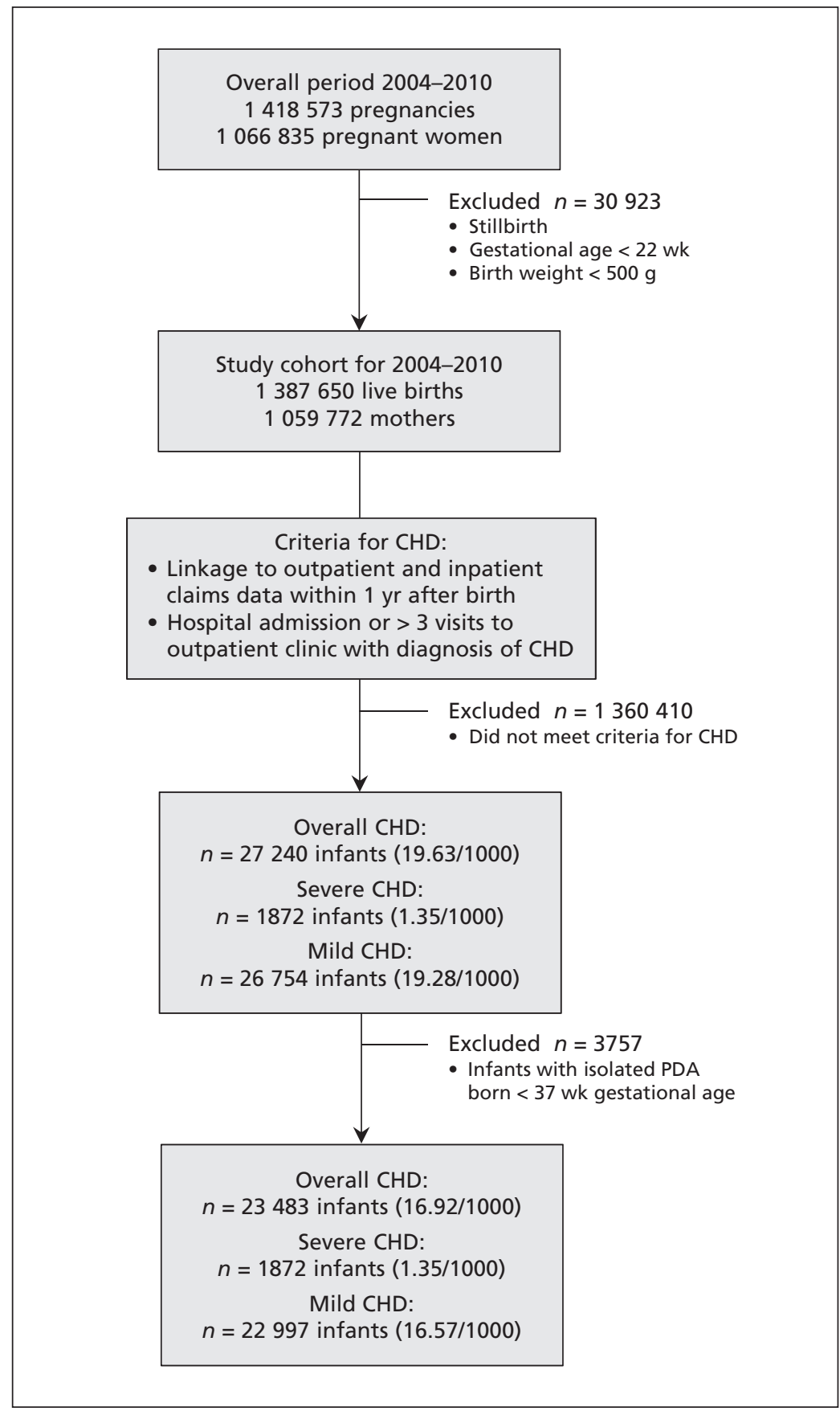

Figure 1: Flow diagram of the study cohort (2004-2010) and identification of infants with congenital heart disease (2004-2011). The overall number of infants with congenital heart disease is less than the sum of those with severe and mild forms because some infants had multiple forms of disease, both mild and severe. Note: $\mathrm{CHD}=$ congenital heart disease, PDA = patent ductus arteriosus. 
experience a higher mortality rate in early life, incomplete coverage of all clinical visits for congenital heart disease could lead to underestimation of prevalence. The current study may not be subject to such underestimation, because we used the Taiwan Maternal and Child Health Database (specifically the Birth Registrations and Birth Notifications data sets), in addition to National Health Insurance claims; we were therefore able to obtain complete medical claims data for infants.

It was not clear why the prevalence of severe congenital heart disease showed a decreasing trend over time. One possible explanation is that more frequent utilization of antenatal diagnostic techniques, especially fetal echocardiography, led more parents to terminate pregnancies with known severe cardiac abnormalities. A previous study found that earlier diagnosis of congenital heart disease was associated with an average 1.4-fold increase in the probability of termination. $^{34}$

In this study, maternal congenital heart defects were associated with an approximately 3 -fold higher rate of congenital heart disease in offspring, consistent with reports from previous studies. ${ }^{14,18}$ Genetic predisposition may have played an important role in this association. Many previous studies have identified significant associations between maternal pregestational type 1 and type 2 diabetes and the risk of congenital heart disease in offspring ${ }^{16-18}$ and have shown that poor glycemic control in the first trimester of pregnancy is associated with an increased risk of congenital heart disease. ${ }^{16}$ Additionally, researchers have postulated a genetic and environmental interaction that leads to disruption of fetal heart development due to the teratogenic impact of high blood glucose levels during the early stages of embryogenesis, especially before the seventh week of gestation. ${ }^{16,35}$

In one previous study, there was a $20 \%-30 \%$ increase in the risk of congenital heart disease in the offspring of mothers with a history of hypertension, ${ }^{36}$ which was in accordance with our results. Chronic hypertension can result in

\begin{tabular}{|c|c|c|c|c|c|c|c|}
\hline \multirow[b]{2}{*}{ Type of CHD } & \multirow[b]{2}{*}{ Total no. } & \multicolumn{5}{|c|}{ Period; prevalence per 1000 live births } & \multirow[b]{2}{*}{$p$ for trend } \\
\hline & & 2004-2005 & 2006-2007 & 2008-2009 & 2010 & $2004-2010$ & \\
\hline Overall & 23483 & 17.24 & 16.82 & 16.33 & 17.75 & 16.92 & 0.4 \\
\hline Severe CHD & 1872 & 1.52 & 1.41 & 1.20 & 1.11 & 1.35 & $<0.001$ \\
\hline Tetralogy of Fallot & 810 & 0.65 & 0.59 & 0.53 & 0.55 & 0.58 & 0.06 \\
\hline Transposition of great arteries & 583 & 0.46 & 0.49 & 0.37 & 0.28 & 0.42 & 0.001 \\
\hline Double outlet of right ventricle & 320 & 0.24 & 0.28 & 0.21 & 0.15 & 0.23 & 0.07 \\
\hline $\begin{array}{l}\text { Total anomalous pulmonary } \\
\text { venous return }\end{array}$ & 224 & 0.16 & 0.17 & 0.02 & 0.14 & 0.16 & 0.7 \\
\hline Common ventricle & 152 & 0.11 & 0.15 & 0.09 & 0.05 & 0.11 & 0.03 \\
\hline Hypoplastic left heart syndrome & 142 & 0.12 & 0.13 & 0.08 & 0.06 & 0.10 & 0.008 \\
\hline Common truncus & 129 & 0.11 & 0.11 & 0.08 & 0.05 & 0.09 & 0.01 \\
\hline Tricuspid atresia & 118 & 0.13 & 0.06 & 0.07 & 0.06 & 0.09 & $<0.001$ \\
\hline $\begin{array}{l}\text { Congenital corrected } \\
\text { transposition of great arteries }\end{array}$ & 34 & 0.03 & 0.02 & 0.03 & 0.02 & 0.03 & 0.6 \\
\hline Mild CHD & 22997 & 16.80 & 16.49 & 16.02 & 17.49 & 16.57 & 0.8 \\
\hline Atrial septal defect & 14284 & 10.34 & 9.99 & 9.88 & 11.89 & 10.29 & 0.009 \\
\hline Patent ductus arteriosus ( $\geq 37 \mathrm{wk}$ ) & 7197 & 5.84 & 5.03 & 4.65 & 5.15 & 5.19 & $<0.001$ \\
\hline Ventricular septal defect & 6830 & 4.85 & 5.14 & 4.93 & 4.57 & 4.92 & 0.4 \\
\hline Pulmonary stenosis & 2679 & 2.10 & 2.05 & 1.68 & 1.77 & 1.93 & $<0.001$ \\
\hline Coarctation of aorta & 656 & 0.48 & 0.46 & 0.45 & 0.55 & 0.47 & 0.7 \\
\hline Endocardial cushion defect & 325 & 0.26 & 0.23 & 0.24 & 0.20 & 0.23 & 0.2 \\
\hline Aortic stenosis & 221 & 0.13 & 0.16 & 0.18 & 0.19 & 0.16 & 0.08 \\
\hline Ebstein anomaly & 62 & 0.05 & 0.04 & 0.05 & 0.03 & 0.05 & 0.8 \\
\hline Cor triatriatum & 26 & 0.02 & 0.02 & 0.02 & 0.02 & 0.02 & 0.8 \\
\hline
\end{tabular}


uteroplacental insufficiency, which leads to compromised blood flow to the developing fetus and increases the risk of congenital heart disease if present early in the pregnancy. Moreover, mothers exposed to certain antihypertensve drugs are at increased risk of delivering infants with cardiovascular malformations. ${ }^{37}$

The current study also showed that maternal epilepsy and mood disorders were associated with an increased risk of congenital heart disease in infants. Previous studies have shown that the use of certain anticonvulsants, ${ }^{38}$ tranquilizers $^{39}$ or hypnotics ${ }^{40}$ is associated with an increased risk of congenital heart disease in offspring. Maternal exposure to certain therapeutic drugs might therefore be a possible explanation for the increased risk among mothers with epilepsy and mood disorders.

Our study also showed that maternal anemia and connective tissue disorders were associated with an increased risk of congenital heart disease in offspring. Similar results were reported

Table 2: Prevalence rates and odds ratios for all congenital heart disease (CHD) in offspring in relation to maternal chronic diseases

\begin{tabular}{|c|c|c|c|c|c|}
\hline \multirow{2}{*}{$\begin{array}{l}\text { Maternal } \\
\text { chronic } \\
\text { disease }\end{array}$} & \multirow{2}{*}{$\begin{array}{l}\text { No. of offspring } \\
\text { with CHD } \\
(n=23483)\end{array}$} & \multirow{2}{*}{$\begin{array}{l}\text { Prevalence per } \\
1000 \text { live births } \\
(95 \% \mathrm{Cl})\end{array}$} & \multicolumn{2}{|c|}{ OR $(95 \% \mathrm{Cl})$} & \multirow[b]{2}{*}{ PAR, $\%$} \\
\hline & & & Unadjusted & Adjusted* & \\
\hline \multicolumn{6}{|c|}{ Diabetes mellitus, type 1} \\
\hline No & 23039 & $16.9(16.7-17.1)$ & Reference & Reference & \\
\hline Yes & 444 & $111.7(81.1-150.1)$ & $7.39(5.41-10.10)$ & $2.32(1.66-3.25)$ & 0.04 \\
\hline \multicolumn{6}{|c|}{ Diabetes mellitus, type 2} \\
\hline No & 22845 & $16.6(16.4-16.8)$ & Reference & Reference & \\
\hline Yes & 638 & $57.9(53.5-62.6)$ & 3.65 (3.36-3.97) & $2.85(2.60-3.12)$ & 1.45 \\
\hline \multicolumn{6}{|c|}{ Hypertension } \\
\hline No & 23000 & $16.7(16.5-16.9)$ & Reference & Reference & \\
\hline Yes & 483 & $42.1(38.4-46.0)$ & $2.59(2.36-2.84)$ & $1.87(1.69-2.07)$ & 0.71 \\
\hline \multicolumn{6}{|c|}{ Thyroid disorders } \\
\hline No & 23153 & $16.9(16.7-17.1)$ & Reference & Reference & \\
\hline Yes & 330 & $19.1(17.0-21.2)$ & $1.13(1.01-1.26)$ & $1.00(0.89-1.12)$ & 0.01 \\
\hline \multicolumn{6}{|c|}{ Congenital heart defects } \\
\hline No & 23380 & $16.9(16.7-17.1)$ & Reference & Reference & \\
\hline Yes & 103 & $54.7(44.7-66.4)$ & $3.31(2.69-4.08)$ & $3.05(2.45-3.80)$ & 0.28 \\
\hline \multicolumn{6}{|l|}{ Anemia } \\
\hline No & 21270 & $16.5(16.3-16.7)$ & Reference & Reference & \\
\hline Yes & 2213 & $22.3(21.4-23.2)$ & $1.35(1.29-1.42)$ & $1.31(1.25-1.38)$ & 2.17 \\
\hline \multicolumn{6}{|c|}{ Connective tissue disorders } \\
\hline No & 23302 & $16.9(16.7-17.1)$ & Reference & Reference & \\
\hline Yes & 181 & $25.4(21.8-29.3)$ & $1.52(1.31-1.76)$ & 1.39 (1.19-1.62) & 0.20 \\
\hline \multicolumn{6}{|l|}{ Epilepsy } \\
\hline No & 23404 & $16.9(16.7-17.1)$ & Reference & Reference & \\
\hline Yes & 79 & $24.3(19.2-30.2)$ & $1.45(1.16-1.82)$ & $1.37(1.08-1.74)$ & 0.09 \\
\hline \multicolumn{6}{|c|}{ Mood disorders } \\
\hline No & 23144 & $16.9(16.6-17.1)$ & Reference & Reference & \\
\hline Yes & 339 & $23.8(21.4-26.5)$ & $1.42(1.27-1.59)$ & $1.25(1.11-1.41)$ & 0.26 \\
\hline \multicolumn{6}{|c|}{ Any of the above } \\
\hline No & 19374 & $16.1(15.8-16.3)$ & Reference & Reference & \\
\hline Yes & 4109 & $26.2(25.4-27.0)$ & $1.59(1.54-1.65)$ & $1.55(1.49-1.61)$ & 5.73 \\
\hline $\begin{array}{l}\text { Note: } \mathrm{Cl}=\mathrm{co} \\
{ }^{*} \text { Estimated } \mathrm{f} \\
\text { nationality, } \\
\text { birth, urbani }\end{array}$ & $\begin{array}{l}\text { nce interval, } O R=0 \\
\text { a multiple logistic re } \\
\text { tal age, level of par } \\
n \text { of the birth site, a }\end{array}$ & $\begin{array}{l}\text { atio, PAR = populatio } \\
\text { ion model with the g } \\
\text { education, birth orde } \\
\text { laternal smoking and }\end{array}$ & $\begin{array}{l}\text { ributable risk. } \\
\text { alized estimating equ } \\
\text { gle v. multiple births, } \\
\text { hol consumption. }\end{array}$ & $\begin{array}{l}\text { on, with adjustment } f c \\
x \text { of the infant, infant' }\end{array}$ & $\begin{array}{l}\text { aternal } \\
\text { ar of }\end{array}$ \\
\hline
\end{tabular}


by Liu and associates. ${ }^{18}$ Anemia is a complex condition that must be studied carefully to determine the underlying causes and the possibility of confounding by other factors associated with inadequate multivitamin or folate supplementation, such as malnutrition. However, the specific reasons for these findings are unknown, and further research is needed. Finally, the factors underlying the association between maternal connective tissue disorders and congenital heart disease in offspring are as yet unknown. Future studies should be conducted to support or refute this finding.

\section{Strengths and limitations}

This study was based on a large sample, which allowed reliable assessment of relations between maternal chronic diseases and specific types of

Table 3: Prevalence rates and odds ratios for mild and severe congenital heart disease (CHD) in offspring in relation to maternal chronic diseases

\begin{tabular}{|c|c|c|c|c|c|c|}
\hline \multirow[b]{2}{*}{$\begin{array}{l}\text { Maternal } \\
\text { chronic } \\
\text { disease }\end{array}$} & \multicolumn{3}{|c|}{ Mild CHD } & \multicolumn{3}{|c|}{ Severe CHD } \\
\hline & $\begin{array}{l}\text { Prevalence per } \\
1000 \text { live births } \\
(95 \% \mathrm{Cl})\end{array}$ & $\begin{array}{l}\text { Unadjusted OR } \\
\quad(95 \% \mathrm{CI})\end{array}$ & $\begin{array}{l}\text { Adjusted OR* } \\
\qquad(95 \% \mathrm{Cl})\end{array}$ & $\begin{array}{l}\text { Prevalence per } \\
1000 \text { live births } \\
(95 \% \mathrm{Cl})\end{array}$ & $\begin{array}{l}\text { Unadjusted OR } \\
\qquad(95 \% \mathrm{Cl})\end{array}$ & $\begin{array}{l}\text { Adjusted OR* } \\
\qquad(95 \% \mathrm{Cl})\end{array}$ \\
\hline \multicolumn{7}{|c|}{ Diabetes mellitus, type 1} \\
\hline No & $16.5(16.3-16.8)$ & Reference & Reference & $1.4(1.3-1.4)$ & Reference & Reference \\
\hline Yes & 111.7 (81.1-149.9) & $7.55(5.52-10.32)$ & $2.39(1.70-3.35)$ & $2.5(0.1-14.1)$ & $1.92(0.27-13.63)$ & $0.73(0.10-5.32)$ \\
\hline \multicolumn{7}{|c|}{ Diabetes mellitus, type 2} \\
\hline No & $16.3(16.0-16.5)$ & Reference & Reference & $1.3(1.3-1.4)$ & Reference & Reference \\
\hline Yes & $56.5(52.1-61.1)$ & $3.63(3.34-3.95)$ & $2.82(2.57-3.10)$ & $4.0(2.9-5.4)$ & $3.04(2.25-4.10)$ & $2.80(2.04-3.85)$ \\
\hline \multicolumn{7}{|c|}{ Hypertension } \\
\hline No & $16.4(16.2-16.6)$ & Reference & Reference & $1.3(1.3-1.4)$ & Reference & Reference \\
\hline Yes & $41.6(37.9-45.5)$ & $2.61(2.37-2.86)$ & 1.89 (1.70-2.09) & $2.3(1.5-3.4)$ & $1.77(1.21-2.59)$ & $1.35(0.90-2.02)$ \\
\hline
\end{tabular}

Thyroid disorders

$\begin{array}{lcccccc}\text { No } & 16.6(16.3-16.8) & \text { Reference } & \text { Reference } & 1.4(1.3-1.4) & \text { Reference } & \text { Reference } \\ \text { Yes } & 18.6(16.6-20.7) & 1.12(1.01-1.26) & 1.00(0.89-1.12) & 1.0(0.6-1.6) & 0.72(0.45-1.17) & 0.73(0.45-1.18)\end{array}$

Congenital heart defects

$\begin{array}{lcccccc}\text { No } & 16.5(16.3-16.7) & \text { Reference } & \text { Reference } & 1.3(1.2-1.4) & \text { Reference } & \text { Reference } \\ \text { Yes } & 52.6(42.8-64.0) & 3.24(2.62-4.01) & 2.97(2.37-3.71) & 9.0(5.3-14.5) & 6.63(4.06-10.83) & 6.72(4.06-11.12)\end{array}$

Anemia

\begin{tabular}{lcccccc} 
No & $16.2(15.9-16.4)$ & Reference & Reference & $1.3(1.2-1.4)$ & Reference & Reference \\
\hline Yes & $21.9(21.0-22.8)$ & $1.36(1.30-1.42)$ & $1.32(1.26-1.38)$ & $1.4(1.2-1.7)$ & $1.07(0.90-1.27)$ & $1.03(0.86-1.23)$
\end{tabular}

Connective tissue disorders

\begin{tabular}{|c|c|c|c|c|c|c|}
\hline No & 16.5 (16.3-16.7) & Reference & Reference & $1.4(1.3-1.4)$ & Reference & Reference \\
\hline Yes & $25.4(21.8-29.3)$ & $1.55(1.34-1.80)$ & $1.42(1.21-1.65)$ & $1.1(0.5-2.2)$ & $0.83(0.38-1.80)$ & $0.88(0.40-1.90)$ \\
\hline \multicolumn{7}{|c|}{ Epilepsy } \\
\hline No & $16.6(16.3-16.8)$ & Reference & Reference & $1.4(1.3-1.4)$ & Reference & Reference \\
\hline Yes & $24.3(19.2-30.2)$ & $1.48(1.18-1.86)$ & 1.39 (1.10-1.77) & $1.8(0.7-4.0)$ & $1.37(0.61-3.05)$ & $1.18(0.49-2.83)$ \\
\hline \multicolumn{7}{|c|}{ Mood disorders } \\
\hline No & 16.5 (16.3-16.7) & Reference & Reference & $1.4(1.3-1.4)$ & Reference & Reference \\
\hline Yes & $23.4(30.0-26.1)$ & $1.43(1.28-1.59)$ & $1.26(1.11-1.42)$ & $1.7(1.1-2.5)$ & $1.25(0.82-1.90)$ & $1.20(0.76-1.87)$ \\
\hline \multicolumn{7}{|c|}{ Any of the above } \\
\hline No & 15.7 (15.5-15.9) & Reference & Reference & $1.3(1.3-1.4)$ & Reference & Reference \\
\hline Yes & $25.7(24.9-26.5)$ & $1.60(1.54-1.66)$ & 1.55 (1.50-1.61) & $1.7(1.5-1.9)$ & $1.28(1.12-1.46)$ & $1.27(1.10-1.46)$ \\
\hline
\end{tabular}

Note: $\mathrm{Cl}=$ confidence interval, $\mathrm{OR}=$ odds ratio.

*Estimated from a multiple logistic regression model with the generalized estimating equation, with adjustment for maternal nationality, parental age, level of parental education, birth order, single v. multiple births, sex of the infant, infant's year of birth, urbanization of the birth site, and maternal smoking and alcohol consumption. 
congenital heart disease. In addition, Taiwan's Birth Registrations data set was considered complete and valid in a previous study. ${ }^{23}$

Some limitations should be noted. We restricted the detection period to the first year of life, which may have resulted in under-identification of congenital heart disease that developed in later years. However, such under-identification would be minimal, given the high frequency of prenatal care ${ }^{41}$ and health checkups during infancy ${ }^{42}$ under National Health Insurance coverage in Taiwan. Although their prevalence was low, some maternal lifestyle factors, including smoking and alcohol consumption, are likely to be underreported in the Birth Notifications data set, relative to previous survey data. ${ }^{43}$ There is also potential for residual confounding because of incomplete consideration of some essential nutritional elements associated with congenital heart disease, including folic acid and multivitamin supplementation, ${ }^{8,9}$ These potential confounders were not available from the data source for this study. We used ICD-9-CM codes, which are not as specific as the ICD-10-CM codes; ${ }^{18}$ this may have led to some misclassification of disease in both mothers and infants. Nonetheless, the prevalences reported here and in the study by $\mathrm{Wu}$ and associates, ${ }^{4}$ who used similar criteria, were generally within the previously reported range. ${ }^{44,45}$ Finally, the decision to exclude live births with birth weight less than $500 \mathrm{~g}$ or gestational age less than 22 weeks was based mainly on expert opinion. Such exclusions are expected to have little influence on our results, since a recent study from Taiwan estimated that the proportion of live births with birth weight less than $500 \mathrm{~g}$ was low $(3.8$ per 10000$){ }^{46}$

\section{Conclusion}

Maternal chronic diseases, including diabetes, hypertension, congenital heart disease, anemia, connective tissue disorders, epilepsy and mood disorders, may predispose mothers to deliver offspring with congenital heart disease. The results of the current study are of value for preconception counselling and identification of high-risk pregnant women. Women with such chronic diseases should control their disease to the extent possible before conception, to minimize the risk of congenital heart disease in their children. For pregnant women who are at high risk, more frequent prenatal screening (with fetal echocardiography) may be warranted. Early recognition of congenital heart disease also permits optimal preparation and care during pregnancy, delivery and the postnatal period.

\section{References}

1. Dolk H, Loane M, Garne E. Congenital heart defects in Europe: prevalence and perinatal mortality, 2000 to 2005. Circulation 2011;123:841-9.

2. Oyen N, Poulsen G, Boyd HA, et al. National time trends in congenital heart defects, Denmark, 1977-2005. Am Heart J 2009; 157:467-473.e1

3. Reller MD, Strickland MJ, Riehle-Colarusso T, et al. Prevalence of congenital heart defects in metropolitan Atlanta, 1998-2005. J Pediatr 2008;153:807-13

4. Wu MH, Chen HC, Lu CW, et al. Prevalence of congenital heart disease at live birth in Taiwan. J Pediatr 2010;156:782-5.

5. Tennant PW, Pearce MS, Bythell M, et al. 20-year survival of children born with congenital anomalies: a population-based study. Lancet 2010;375:649-56.

6. Wren C, Irving CA, Griffiths JA, et al. Mortality in infants with cardiovascular malformations. Eur J Pediatr 2012;171:281-7.

7. Wilson PD, Loffredo CA, Correa-Villaseñor A, et al. Attributable fraction for cardiac malformations. Am J Epidemiol 1998;148:414-23.

8. Botto LD, Mulinare J, Erickson JD. Occurrence of congenital heart defects in relation to maternal mulitivitamin use. Am J Epidemiol 2000;151:878-84

9. Czeizel AE. Periconceptional folic acid containing multivitamin supplementation. Eur J Obstet Gynecol Reprod Biol 1998;78: 151-61.

10. Blomberg MI, Källén B. Maternal obesity and morbid obesity: the risk for birth defects in the offspring. Birth Defects Res A Clin Mol Teratol 2010;88:35-40.

11. Burd L, Deal E, Rios R, et al. Congenital heart defects and fetal alcohol spectrum disorders. Congenit Heart Dis 2007;2:250-5.

12. Malik S, Cleves MA, Honein MA, et al.; National Birth Defects Prevention Study. Maternal smoking and congenital heart defects. Pediatrics 2008;121:e810-6.

13. Gibson S, Lewis KC. Congenital heart disease following maternal rubella during pregnancy. AMA Am J Dis Child 1952;83:317-9.

14. Khairy P, Ouyang DW, Fernandes SM, et al. Pregnancy outcomes in women with congenital heart disease. Circulation 2006;113:517-24.

15. Aberg A, Westbom L, Källén B. Congenital malformations among infants whose mothers had gestational diabetes or preexisting diabetes. Early Hum Dev 2001;61:85-95.

16. Lisowski LA, Verheijen PM, Copel JA, et al. Congenital heart disease in pregnancies complicated by maternal diabetes mellitus. An international clinical collaboration, literature review, and meta-analysis. Herz 2010;35:19-26.

17. Nielsen GL, Nørgard B, Puho E, et al. Risk of specific congenital abnormalities in offspring of women with diabetes. Diabet Med 2005;22:693-6.

18. Liu S, Joseph KS, Lisonkova S, et al. Association between maternal chronic conditions and congenital heart defects: a population-based cohort study. Circulation 2013;128:583-9.

19. Fixler DE, Pastor P, Sigman E, et al. Ethnicity and socioeconomic status: impact on the diagnosis of congenital heart disease. J Am Coll Cardiol 1993;21:1722-6.

20. Wang Y, Liu G, Druschel CM, et al. Maternal race/ethnicity and survival experience of children with congenital heart disease. J Pediatr 2013;163:1437-42.e1-2.

21. National Center for Health and Welfare data analysis and application. Taipei (Taiwan): Ministry of Health and Welfare; 2014 Available: www.mohw.gov.tw/cht/DOS/DM1.aspx?f_list_ no=812 (accessed 2016 May 15).

22. Wu TP, Liang FW, Huang YL, et al. Maternal mortality in Taiwan: a nationwide data linkage study. PLoS One 2015;10:e0132547.

23. Lin CM, Lee PC, Teng SW, et al. Validation of the Taiwan Birth Registry using obstetric records. J Formos Med Assoc 2004;103:297-301.

24. Chang YT, Liu CC, Tsai LM, et al. Separate and joint effects of diabetes mellitus and chronic kidney disease on the risk of acute coronary syndrome: a population-based cohort study. Medicine (Baltimore) 2014;93:e261.

25. Wang WL, Sung YT, Sung FC, et al. Low birth weight, prematurity, and paternal social status: impact on the basic competence test in Taiwanese adolescents. J Pediatr 2008;153:333-8.

26. Marelli AJ, Mackie AS, Ionescu-Ittu R, et al. Congenital heart disease in the general population: changing prevalence and age distribution. Circulation 2007;115:163-72.

27. Statistics of marriage. Taipei (Taiwan): Ministry of Interior; 2015. Available: www.moi.gov.tw/stat/news_content.aspx?sn=9169 (accessed 2016 Apr. 8)

28. Yeh SJ, Chen HC, Lu CW, et al. Prevalence, mortality, and the disease burden of pediatric congenital heart disease in Taiwan. Pediatr Neonatol 2013;54:113-8.

29. Tan HF, Tseng HF, Chang CK, et al. Accessibility assessment of the Health Care Improvement Program in rural Taiwan. $J$ Rural Health 2005;21:372-7.

30. Burton P, Gurrin L, Sly P. Extending the simple linear regression model to account for correlated responses: an introduction 
to generalized estimating equations and multi-level mixed modelling. Stat Med 1998;17:1261-91.

31. Cole P, MacMahon B. Attributable risk percent in case-control studies. Br J Prev Soc Med 1971;25:242-4.

32. van der Bom T, Zomer AC, Zwinderman AH, et al. The changing epidemiology of congenital heart disease. Nat Rev Cardiol 2011;8:50-60.

33. Administration of national health insurance. National Health Insurance Act. Taipei (Taiwan): Ministry of Health and Welfare; 2011. Available: http://law.moj.gov.tw/Eng/LawClass/LawAll. aspx ?PCode=L0060001 (accessed 2016 Apr. 10).

34. Germanakis I, Sifakis S. The impact of fetal echocardiography on the prevalence of liveborn congenital heart disease. Pediatr Cardiol 2006;27:465-72.

35. Mills JL, Baker L, Goldman AS. Malformations in infants of diabetic mothers occur before the seventh gestational week. Implications for treatment. Diabetes 1979;28:292-3.

36. Bateman BT, Huybrechts KF, Fischer MA, et al. Chronic hypertension in pregnancy and the risk of congenital malformations: a cohort study. Am J Obstet Gynecol 2015;212:337.e1-14.

37. Caton AR, Bell EM, Druschel CM, et al. Antihypertensive medication use during pregnancy and the risk of cardiovascular malformations. Hypertension 2009;54:63-70.

38. Kelly TE, Edwards P, Rein M, et al. Teratogenicity of anticonvulsant drugs. II: a prospective study. Am J Med Genet 1984;19:435-43.

39. Bracken MB, Holford TR. Exposure to prescribed drugs in pregnancy and association with congenital malformations. Obstet Gynecol 1981;58:336-44.

40. Rothman KJ, Fyler DC, Goldblatt A, et al. Exogenous hormones and other drug exposures of children with congenital heart disease. Am J Epidemiol 1979;109:433-9.

41. Lin HC, Lin YJ, Hsiao FH, et al. Prenatal care visits and associated costs for treatment-seeking women with depressive disorders. Psychiatr Serv 2009;60:1261-4.

42. Maternal and child health. Taipei (Taiwan): National Statistics; 2014. Available: http://eng.stat.gov.tw/public/Attachment/ 410184439IGBKG0IN.pdf (accessed 2016 Mar. 26).

43. Ko TJ, Tsai LY, Chu LC, et al. Parental smoking during pregnancy and its association with low birth weight, small for ges- tational age, and preterm birth offspring: a birth cohort study. Pediatr Neonatol 2014;55:20-7.

44. Hoffman JI, Kaplan S. The incidence of congenital heart disease. J Am Coll Cardiol 2002;39:1890-900.

45. Sayasathid J, Sukonpan K, Somboonna N. Epidemiology and etiology of congenital heart diseases. In: Rao PS, editor. Congenital heart disease: selected aspects. Rijeka (Croatia): InTech; 2012.

46. Liang FW, Lu TH, Wu MH, et al. International ranking of infant mortality rates: Taiwan compared with European countries. Pediatr Neonatol 2016;57:326-32.

Affiliations: Department of Pediatrics (Chou), Ditmanson Medical Foundation Chia-Yi Christian Hospital, Chiayi, Taiwan; Department of Applied Life Science and Health (Chou), College of Human Ecology, Chia Nan University of Pharmacy and Science, Tainan, Taiwan; Institute of Public Health, College of Medicine (Chiou, Liang, Lu, Li), National Cheng Kung University, Tainan, Taiwan; Department of Statistics (Chen), Ministry of Health and Welfare, Taipei, Taiwan; Department of Public Health (Li), College of Public Health, China Medical University, Taichung, Taiwan

Contributors: Hsin-Hsu Chou, Meng-Jiun Chiou and Chung-Yi Li conceived and designed the study. Hsin-Hsu Chou and Meng-Jiun Chiou collected the data and drafted the manuscript. Fu-Wen Liang, Lea-Hua Chen and Tsung-Hsueh Lu were involved in the acquisition and analysis of data. All of the authors critically revised the manuscript for important intellectual content. All of the authors approved the final version for publication and agreed to act as guarantors of the work. Hsin-Hsu Chou and Meng-Jiun Chiou contributed equally to this paper.

Funding: This work was supported by a grant from the Ministry of Science and Technology (MOST 104-2314-B-006-019). The funder had no role in conducting or submitting this work. 